\title{
Pharmacists' Attitudes and Role in Diabetes Management in Kuwait
}

\author{
Asmaa A. Al Haqan ${ }^{\text {a }}$ Dalal M. Al-Taweel ${ }^{\mathrm{a}} \quad$ Abdelmoneim Awad ${ }^{\mathrm{a}}$ \\ Deborah Jane Wake ${ }^{b}$ \\ a Department of Pharmacy Practice, Faculty of Pharmacy, Kuwait University, Safat, Kuwait; \\ ${ }^{b}$ Department of Molecular and Clinical Medicine, Medical School, University of Dundee, Dundee, UK
}

\section{Keywords}

Pharmacy services · Diabetes · Attitudes · Kuwait

\begin{abstract}
Objectives: The objectives of this study were to measure pharmacists' attitudes toward management of diabetes, identify current levels of pharmacy service provided to patients with diabetes, and identify barriers for further provision of diabetes-related services. Subjects and Methods: A descriptive, cross-sectional study was conducted on a sample of 198 pharmacists working in primary and secondary health care settings in one health region of Kuwait using a pretested self-administered questionnaire. Descriptive statistics, correlations, and comparative analysis were performed. Results: The response rate was $84.4 \%(n=168)$. Respondents had overall positive attitudes toward management of diabetes. Pharmacists regularly provided their patients with counseling on the appropriate time to administer their medications; however, services related to hypoglycemia and management of comorbid diseases were rarely provided. A negative correlation was found between the positive overall diabetes-related attitudes and pharmacists' involvement in providing the following diabetes-related services: glucose monitoring $(r=-0.25, p=0.001)$, comorbid
\end{abstract}

\begin{tabular}{ll}
\hline KARGER & @ 2017 S. Karger AG, Basel \\
$\begin{array}{l}\text { E-Mail karger@karger.com } \\
\text { www.karger.com/mpp }\end{array}$ & $\begin{array}{l}\text { Karger } \\
\text { This is an Open Access article licensed under the terms of the } \\
\text { Creative Commons Attribution-NonCommercial 3.0 Un- } \\
\text { ported license (CC BY-NC) (www.karger.com/OA-license), } \\
\text { applicable to the online version of the article only. Distribu- } \\
\text { tion permitted for non-commercial purposes only. }\end{array}$
\end{tabular}

disease management $(r=-0.243, p=0.001)$, and healthy living choices $(r=-0.237, p=0.002)$. The perception that some physicians and patients have of pharmacists as dispensers only was identified as the most important barrier to providing diabetes-related services. Conclusion: Pharmacists have positive diabetes-related attitudes; however, they provide limited diabetes-related services to their patients. Barriers to provision of pharmacy services to patients with diabetes should be addressed to enable optimum patient care delivery.

(c) 2017 S. Karger AG, Basel

\section{Introduction}

International standards for diabetes care have recognized the crucial role of pharmacists in diabetes management $[1,2]$. Pharmacists may provide many services beyond dispensing medications, including management of medication therapy, reconciliation of medication, preventive care services such as screening and immunization, as well as education and behavioral counseling [1, 2]. Collaboration among physicians, nurses, dieticians, and pharmacists is required to ensure optimum patient care and adequate diabetes management [3-6]. Health

Asmaa A. Al-Haqan, BPharm, MSc Clinical Pharmacy

Department of Pharmacy Practice

Faculty of Pharmacy, Kuwait University

PO Box 24923 Safat 13110 (Kuwait)

E-Mail asmaa_h@hsc.edu.kw 
care settings that adopt a multidisciplinary team approach in the management of diabetes improve efficiency and cost-effectiveness of diabetes care $[3,4]$. The interventions of pharmacists have been proven to improve glycemic control $[3,5,6]$, empower patients to self-management [7], and increase patients' satisfaction and quality of life [8-10].

A report from the National Diabetes Commission suggested that an inappropriate attitude of health care professionals toward diabetes could lead to poor patient outcomes [11]. This led to the development of the Diabetes Attitudes Scale (DAS) in 1989 [12]. The DAS was designed to measure diabetes-related attitudes/beliefs, and following several modifications is now in its third version [13]. Previous studies had indicated that pharmacists' attitudes toward diabetes are generally positive [14-16]; however, this might not correlate with the degree of their involvement in diabetes patient education $[14,15]$. The frequency of providing diabetes-related services varied throughout the different studies $[15,16]$. This could be linked to the diverse practice settings, evolving role of the pharmacists, differences in teaching curricula of pharmacy schools, pharmacists becoming more involved in direct patient care, and cultural diversity. Moreover, the current literature provides limited information on types of services provided by pharmacists in different practice settings (community, primary care, and hospital) and whether the setting has an impact on attitudes $[15,16]$.

Although globally the pharmacist's role has changed from dispensing to drug therapy management, the pharmacist's role in Kuwait is still largely limited to dispensing and pharmacy administration (e.g., stock management, medication orders, and record keeping) [17]. There is a lack of clear local guidelines clarifying patient-related pharmacists' activities. The present study was therefore designed to measure pharmacists' attitude toward diabetes management, to identify pharmacy services that are currently provided to patients with diabetes in Kuwait, and determine whether or not these activities differ between primary and secondary health care settings, and to identify barriers to provision of additional diabetes-related services.

\section{Subjects and Methods}

\section{Study Design and Population}

A descriptive, cross-sectional survey-based study was conducted in Kuwait, a Middle-Eastern country with an estimated population of $3,065,850$ people; $35.6 \%$ of whom are Kuwaitis (2011 estimate) [18]. The survey was conducted during the period of Febru- ary to April 2015. Kuwait is divided into 6 health care regions in which there are a total of 6 public general hospitals and 79 public primary care clinics in addition to several private hospitals and clinics. Diabetes clinics are run in primary care clinics and in all general hospitals in Kuwait.

Convenience sampling was used to choose 1 health region: Hawalli Health Region. All pharmacists working in primary and secondary health care settings in Hawalli Health Region were included in the study $(n=198)$. In this study, the term "primary care" is defined as the first point of contact for patients with health care, where the services are provided by a primary care physician (general practitioner or family physician). In Kuwait this is usually a polyclinic. The term "secondary care" is defined as health care services provided by specialists in a hospital setting (outpatient or inpatient), which includes acute care in hospital emergency departments. The Ethics Review Committee of Dasman Diabetes Institute, Kuwait, approved the study, and also permission was obtained from the necessary governing bodies of the respective primary care polyclinics, private hospitals, and public hospitals in the Ministry of Health, Kuwait.

\section{Questionnaire Design}

The questionnaire contained 4 different sections: (a) participants' demographics, (b) measured participants' attitude toward diabetes using the Diabetes Attitude Scale-Version 3 (DAS-3) [13], (c) a list of possible diabetes patient support activities that could be delivered by pharmacists, and (d) a list of barriers to providing more diabetic services to patients.

The DAS-3 was used to measure participants' degree of agreement to 33 diabetes-related statements, on a 5-point Likert type scale (strongly disagree: 1; disagree: 2; neutral: 3; agree: 4 , and strongly agree: 5 ). The list of possible diabetes-related services was constructed based on a literature review $[3,4,15,16,19]$ of the role of pharmacists in diabetes management. In this section, the frequency of providing relevant information/activities to patients was measured as: never $=0 \%$, rarely $=25 \%$, often $=75 \%$, or always $=$ $100 \%$. The barriers investigated included the perception that some physicians or patients have of pharmacists as dispensers only, lack of collaboration with other health care providers, lack of organization, administrative factors, inadequate documentation, and lack of facilities (e.g., counseling room). Content and face validity of the questionnaire were established by means of a pilot study on 11 pharmacists, and changes were made as necessary prior to roll-out. The questionnaire used in this study is available online (see suppl. online material; see www.karger.com/doi/10.1159/000456088 for all online suppl. material).

\section{Data Collection}

One hundred and ninety-eight pharmacists were approached; the questionnaires were given to those who agreed to participate and they were completed anonymously. Questionnaires were distributed in person by the researcher. All sites were visited once to distribute the questionnaires and subsequently to collect them. Subsequent visits were done as a reminder to those participants who did not complete the questionnaire at the first visit. All participants signed an informed consent form and were informed about the confidentiality of the collected data before participation. Incentives were not offered for completion of the questionnaire. The time required for completion of the questionnaire was around 15-20 min. Negatively worded items were 
Table 1. Demographic and other characteristics of respondents $(n=168)$

\begin{tabular}{|c|c|}
\hline Parameter & $n(\%)$ \\
\hline \multicolumn{2}{|l|}{ Age (years) } \\
\hline $20-29$ & $61(36.3)$ \\
\hline $30-39$ & $71(42.3)$ \\
\hline$\geq 40$ & $36(21.4)$ \\
\hline \multicolumn{2}{|l|}{ Gender } \\
\hline Male & $74(44.0)$ \\
\hline Female & $94(56.0)$ \\
\hline \multicolumn{2}{|l|}{ Years of practice } \\
\hline$\leq 5$ & $59(35.1)$ \\
\hline $6-10$ & $32(19.0)$ \\
\hline$>10$ & $77(45.9)$ \\
\hline \multicolumn{2}{|l|}{ Practice Site } \\
\hline Primary care & $44(26.2)$ \\
\hline Secondary Care & $124(73.8)$ \\
\hline \multicolumn{2}{|l|}{ Educational level } \\
\hline BPharm & $144(85.7)$ \\
\hline MPharm & $16(9.5)$ \\
\hline PharmD & $2.0(1.2)$ \\
\hline $\mathrm{MSc}$ & $5.0(3.0)$ \\
\hline $\mathrm{PhD}$ & $1(0.6)$ \\
\hline \multicolumn{2}{|c|}{ Country of graduation } \\
\hline Kuwait & $55(32.7)$ \\
\hline Other & $113(67.3)$ \\
\hline \multicolumn{2}{|c|}{ Is diabetes an area that interests you? } \\
\hline Yes & $135(80.4)$ \\
\hline No & $33(19.6)$ \\
\hline \multicolumn{2}{|c|}{$\begin{array}{l}\text { Have you ever completed special diabetes continuing education } \\
\text { in the past? }\end{array}$} \\
\hline Yes & $42(25.0)$ \\
\hline No & $126(75.0)$ \\
\hline
\end{tabular}

rescored with the appropriate scale conversion so that the higher scores on all items reflected more positive attitudes towards a factor [11].

\section{Data Analysis}

Data analysis was accomplished using IBM SPSS Statistics for Windows, version 22 (IBM Corp., Armonk, N.Y., USA). Demographic characteristics were summarized using frequencies and percentages. Respondents' attitudes toward diabetes were presented as medians and interquartile range (IQR). Statistical correlational analysis (Spearman's rank correlation) was used to measure the association between diabetes attitudes and provision of diabetes services to patients. Mann-Whitney and Kruskal-Wallis tests were used to evaluate the differences in medians between the groups of predictor variables, and diabetes attitudes subscales and diabetes services. Statistical significance for all analysis was defined as $p<0.05$. The predictor variables were categorized as follows: (a) age: $20-29 ; 30-39 ; 40-49$, and $\geq 50$ years; (b) gender: male and female; (c) years of practice: $0-5 ; 6-10$, and $>10$ years; (d) practice sites: primary care or secondary care; (e) level of education: first degree (BPharm, Mpharm, and PharmD) and postgraduate degree
Table 2. Diabetes Attitude Scale-Version 3 (DAS-3) and subscale scores $(n=168)$

\begin{tabular}{lll}
\hline & Items, $n$ & Median (IQR) \\
\hline Total DAS-3 & 33 & $3.8(3.6-4.0)$ \\
Five subsets of DAS-3 & & \\
$\quad$ Need for special training & 5 & $4.4(4.0-4.8)$ \\
$\quad$ Seriousness of type 2 diabetes & 7 & $3.8(3.3-4.1)$ \\
$\quad$ Value of tight control & 7 & $3.6(3.2-3.9)$ \\
$\quad$ Psychosocial impact of DM & 6 & $3.8(3.5-4.27)$ \\
$\quad$ Patient autonomy & 8 & $3.6(3.4-3.9)$ \\
\hline \multicolumn{1}{l}{ IQR, Interquartile range. } & & \\
\hline
\end{tabular}

(MSc and $\mathrm{PhD}$ ); (f) university: Kuwait University and non-Kuwait University graduates; (g) interest in diabetes: yes, no; and (h) special diabetes continuing education in the past: yes, no.

With regards to the diabetes-related services, the internal consistency for each group of diabetes services that pharmacists may provide to patients with diabetes was assessed using Cronbach $a$ test. The test results were as follows: 5 statements of blood glucose monitoring (0.88), 3 statements of hypoglycemia management (0.85), 10 statements of general pharmacotherapy management including insulin and oral antidiabetic drugs (0.87), 9 statements of comorbid disease management (0.92), and 4 statements of healthy living choices (0.82).

\section{Results}

Of the 198 pharmacists approached, 168 (84.8\%) agreed to participate and completed the questionnaire. Respondents' demographic characteristics are shown in Table 1. Of the 168 respondents, 71 (42.3\%) were in the age group of 30-39 years. The majority of respondents $(n=94 ; 56 \%)$ were female, $135(80.4 \%)$ of the respondents indicated an interest in diabetes, but $126(75 \%)$ did not complete special diabetes continuing education.

The overall DAS-3 and subsets scores are given in Table 2. In general, all the respondents expressed positive attitudes in all DAS-3 subscales. Higher positive attitudes were found among all the participants scoring high in the "need for special training in education" subscale (median 4.4, IQR [4.0 - 4.8]) compared to other subscales. In comparison with secondary care pharmacists, it was found that pharmacists working in primary care $(n=44,26.2 \%)$ held significantly more positive attitudes with regards to the psychosocial impact of the diabetes subscale $(p=$ 0.01 ). There were no significant differences between those working in primary and secondary care regarding the overall DAS-3 and other subscales $(p>0.05)$. 
Table 3. Frequency of providing diabetes-related services to patients with diabetes $(n=168)$

\begin{tabular}{|c|c|c|c|c|c|}
\hline & \multicolumn{4}{|c|}{$\begin{array}{l}\text { Frequency of providing this service to } \\
\text { patients, } n(\%)\end{array}$} & \multirow[t]{2}{*}{$\begin{array}{l}\text { Median } \\
\text { (IQR) }\end{array}$} \\
\hline & Never & Rarely & Often & Always & \\
\hline \multicolumn{6}{|l|}{ Services related to blood glucose monitoring } \\
\hline Counsel on the use of a blood glucose meter, including how to obtain a blood sample & $64(38.1)$ & $41(24.4)$ & $37(22.0)$ & $26(15.5)$ & $2(1-3)$ \\
\hline Counsel on the appropriate times to check blood glucose & $43(25.6)$ & $57(33.9)$ & $51(30.4)$ & $17(10.1)$ & $2(1-3)$ \\
\hline Counsel on the current treatment targets for blood glucose & $34(20.2)$ & $51(30.4)$ & $61(36.3)$ & $22(13.1)$ & $2(2-3)$ \\
\hline Counsel on the interpretation of $A_{1 C}$ results & $52(31.0)$ & $59(35.1)$ & $47(28.0)$ & $10(6.0)$ & $2(1-3)$ \\
\hline $\begin{array}{l}\text { Provide drug therapy recommendations to the physician to help the patient reach blood } \\
\text { glucose targets }\end{array}$ & $47(28.0)$ & $56(33.3)$ & $38(22.6)$ & $27(16.1)$ & $2(1-3)$ \\
\hline Overall median & & & & & $2(1-3)$ \\
\hline \multicolumn{6}{|l|}{ Services related to hypoglycemia management } \\
\hline Counsel on signs and symptoms of hypoglycemia & $22(13.1)$ & $59(35.1)$ & $56(33.3)$ & $31(18.5)$ & $3(2-3)$ \\
\hline Identify possible causes of hypoglycemia & $20(11.9)$ & $65(38.7)$ & $58(34.5)$ & $25(14.9)$ & $2(2-3)$ \\
\hline Provide recommendations for treatment of hypoglycemia to the patient & $21(12.5)$ & $46(27.4)$ & $68(40.5)$ & $33(19.6)$ & $3(2-3)$ \\
\hline Overall median & & & & & $3(2-3)$ \\
\hline \multicolumn{6}{|l|}{ Services related to pharmacotherapy } \\
\hline \multicolumn{6}{|l|}{ Conduct a drug history, including } \\
\hline Prescription medications & $18(10.7)$ & $45(26.8)$ & $49(29.2)$ & $56(33.3)$ & $3(2-4)$ \\
\hline Over-the-counter products & $32(19.0)$ & $48(28.6)$ & $62(36.9)$ & $26(15.5)$ & $3(2-3)$ \\
\hline Herbal and natural products & $38(22.6)$ & $55(32.7)$ & $51(30.4)$ & $24(14.3)$ & $2(2-3)$ \\
\hline Review the patient's drug refill history to identify poor adherence & $26(15.5)$ & $51(30.4)$ & $54(32.1)$ & $37(22.0)$ & $3(2-3)$ \\
\hline Counsel on the appropriate use of syringes and needles (e.g., sharp disposal) & $18(10.7)$ & $36(21.4)$ & $71(42.3)$ & $43(25.6)$ & $3(2-4)$ \\
\hline Counsel on the appropriate use of insulin pens & $9(5.4)$ & $28(16.7)$ & $74(44.0)$ & $57(33.9)$ & $3(3-4)$ \\
\hline Counsel on the appropriate storage of insulin & $7(4.2)$ & $21(12.5)$ & $61(36.3)$ & $79(47.0)$ & $3(3-4)$ \\
\hline $\begin{array}{l}\text { Counsel on appropriate insulin administration (mixing insulin, injection technique, } \\
\text { timing of injection, rotation of sites) }\end{array}$ & $11(6.5)$ & $40(23.8)$ & $56(33.3)$ & $61(36.3)$ & $3(2-4)$ \\
\hline Describe the appropriate time to administer each oral antidiabetic drug & $5(3.0)$ & $12(7.1)$ & $52(31.0)$ & $99(58.9)$ & $4(3-4)$ \\
\hline Describe potential adverse effects of each oral antidiabetic drug & $10(6.0)$ & $51(30.4)$ & $70(41.7)$ & $37(22.0)$ & $3(2-3)$ \\
\hline Overall median & & & & & $3(2-3)$ \\
\hline \multicolumn{6}{|l|}{ Services related to comorbid disease management } \\
\hline Recommend antiplatelet therapy to the patient's physician & $70(41.7)$ & $50(29.8)$ & $31(18.5)$ & $17(10.1)$ & $2(1-3)$ \\
\hline Provide education on the importance of controlling blood pressure in diabetes & $26(15.5)$ & $59(35.1)$ & $58(34.5)$ & $25(19.9)$ & $2(2-3)$ \\
\hline $\begin{array}{l}\text { Provide drug therapy recommendations to the physician to help the patient reach blood } \\
\text { pressure targets }\end{array}$ & $55(32.7)$ & $48(28.6)$ & $46(27.4)$ & $19(11.3)$ & $2(1-3)$ \\
\hline $\begin{array}{l}\text { Provide education on the importance of regular screening of nephropathy } \\
\text { (e.g., type of test, where to get the test, how often to test) }\end{array}$ & $50(29.8)$ & $56(33.3)$ & $39(23.2)$ & $23(13.7)$ & $2(1-3)$ \\
\hline Review the patient's drug profile to identify drugs that are renally cleared & $56(33.3)$ & $52(31.0)$ & $35(20.8)$ & $25(14.9)$ & $2(1-3)$ \\
\hline Provide education on the importance of regular screening for neuropathic pain & $50(29.8)$ & $59(35.1)$ & $39(23.2)$ & $20(11.9)$ & $2(1-3)$ \\
\hline Provide education on the importance of regular screening for retinopathy & $50(29.8)$ & $56(33.3)$ & $46(27.4)$ & $16(9.5)$ & $2(1-3)$ \\
\hline Counsel on good foot care techniques & $46(27.4)$ & $49(29.2)$ & $47(28.0)$ & $26(15.5)$ & $2(1-3)$ \\
\hline Provide education on the importance of diabetes foot care & $47(28.0)$ & $53(31.5)$ & $38(22.6)$ & $31(17.9)$ & $2(1-3)$ \\
\hline Overall median & & & & & $2(1-3)$ \\
\hline \multicolumn{6}{|l|}{ Services related to healthy living choices } \\
\hline $\begin{array}{l}\text { Provide education about the importance of immunization for influenza and } \\
\text { pneumococcal pneumonia in diabetes }\end{array}$ & $72(42.9)$ & $52(31.0)$ & $33(19.6)$ & $11(6.5)$ & $2(1-3)$ \\
\hline Provide basic information on diet as it relates to diabetes management & $26(15.5)$ & $51(30.4)$ & $66(39.3)$ & $25(14.9)$ & $3(2-3)$ \\
\hline Provide basic information on exercise as it relates to diabetes management & $23(13.7)$ & $49(29.2)$ & $69(41.1)$ & $27(16.1)$ & $3(2-3)$ \\
\hline Overall median & & & & & $2(2-3)$ \\
\hline
\end{tabular}

Younger pharmacists aged $20-29$ years $(n=61 ; 36.3 \%)$ and $30-39$ years $(n=71 ; 42.3 \%)$ had significantly more positive attitudes toward the need for special training compared to the group aged $\geq 40$ years $(n=36 ; 21.4 \%)$ ( $p=0.03$ and 0.02 , respectively). Female pharmacists $(n=94 ; 56.0 \%)$ held more positive attitudes regarding the value of tight control of blood glucose than male pharmacists $(n=74 ; 44.0 \%)(p=0.01)$. In addition, pharmacists who graduated from Kuwait University $(n=55 ; 32.7 \%)$ had the following more significantly compared to graduates from other universities $(n=113 ; 67.3 \%)$ : positive overall attitudes towards diabetes $(p=0.01)$, the need for special training ( $p=0.03$ ), the severity of type 2 diabetes $(p=0.001)$, and the value of tight control of blood glucose $(p=0.005)$. There were no significant differences between the other respondents' characteristics and their diabetesrelated attitudes $(p>0.05)$. 
Table 4. Correlations between DAS-3 subscales and all groups of diabetes services ( $r$ values)

\begin{tabular}{|c|c|c|c|c|c|}
\hline & $\begin{array}{l}\text { Blood glucose } \\
\text { monitoring }\end{array}$ & $\begin{array}{l}\text { Hypoglycemia } \\
\text { management }\end{array}$ & $\begin{array}{l}\text { Pharmacotherapy } \\
\text { management }\end{array}$ & $\begin{array}{l}\text { Comorbid disease } \\
\text { management }\end{array}$ & $\begin{array}{l}\text { Healthy living } \\
\text { choices }\end{array}$ \\
\hline DAS-3 & $-0.251^{* *}$ & $-0.173^{*}$ & -0.104 & $-0.243^{* *}$ & $-0.237^{* *}$ \\
\hline Need for special training & -0.139 & $-0.224^{* *}$ & -0.039 & $-0.198^{*}$ & -0.100 \\
\hline Seriousness of type 2 diabetes & $-0.173^{*}$ & -0.081 & -0.081 & $-0.212^{* *}$ & $-0.231^{* *}$ \\
\hline Value of tight control & $-0.386^{* *}$ & $-0.316^{* *}$ & $-0.219^{* *}$ & $-0.277^{* *}$ & $-0.283^{* *}$ \\
\hline Psychosocial impact of DM & -0.073 & -0.107 & -0.051 & -0.091 & -0.049 \\
\hline Patient autonomy & 0.003 & 0.122 & -0.017 & 0.028 & -0.005 \\
\hline
\end{tabular}

DAS-3, Diabetes Attitude Scale-Version 3; DM, diabetes mellitus. * Correlation is significant at the 0.05 level (2-tailed). ${ }^{* *}$ Correlation is significant at the 0.01 level (2-tailed).

The frequency of providing services to patients with diabetes is shown in Table 3. The overall medians (IQR) for each group of services were as follows: blood glucose monitoring: 2(1-3), hypoglycemia management: $3(2-3)$, general pharmacotherapy management including insulin and oral antidiabetic drugs: $3(2-3)$, comorbid disease management: $2(1-3)$, and healthy living choices: $2(2-3)$.

In general, pharmacists provided limited diabetes services to patients, with no significant differences between those working in primary and secondary care $(p>0.05)$. Respondents aged $30-39$ years $(n=71 ; 42.3 \%)$ and $\geq 40$ years $(n=36 ; 24.1 \%)$ provided the following services to patients more frequently than the younger age group $(n=61 ; 36.3 \%)$ : blood glucose monitoring $(p=0.001$ and 0.004 , respectively), hypoglycemia management $(p=0.02$ and 0.04 , respectively), general pharmacotherapy management including insulin and oral antidiabetic drugs $(p=0.003$ and 0.005 , respectively), comorbid disease management ( $p=0.04$ and $<0.001$, respectively), and healthy living choices ( $p=0.04$ and 0.009 , respectively). Male pharmacists $(n=74 ; 44 \%)$ more frequently provided activities related to blood glucose monitoring $(p=$ $0.03)$ and hypoglycemia management $(p=0.02)$ than female pharmacists. Pharmacists practicing for more than 10 years $(n=77 ; 45.9 \%)$ more frequently provided services such as blood glucose monitoring $(p=0.03)$, hypoglycemia management $(p=0.01)$, general pharmacotherapy management including insulin and oral antidiabetic drugs $(p=0.004)$, and comorbid disease management $(p=0.01)$ compared to those with less experience. Moreover, graduates not from Kuwait University $(n=113$; 67.3) provided diabetes services to patients more frequently $(p<0.001)$ than graduates of Kuwait University. There were no significant differences between the type of diabetes services provided to patients and respondents'

Pharmacists' Role in Diabetes Management educational level, interest in diabetes, and completion of special diabetes continuing education $(p>0.05)$.

The correlations between DAS-3 subscales and all groups of diabetic services are shown in Table 4 . The respondents with overall more positive diabetes-related attitudes were less frequently involved in providing glucose monitoring, comorbid disease management, and healthy living choices.

Respondents identified "the image that some physicians or patients have of pharmacists as dispensers only" as the most important barrier to providing diabetes care to patients and "lack of facilities (e.g., counseling room)" as the least important barrier. Other potential barriers in decreasing order included lack of collaboration with other health care providers, lack of organization, administrative factors, and inadequate documentation.

\section{Discussion}

The key findings of this study showed that pharmacists had a general positive attitude toward diabetes management. The most positive attitude was "the need for special training in patient education." Despite their positive attitude, they rarely provided advanced diabetes services to their patients, such as comorbid disease management. They regularly provided basic services such as patient counseling. The most important barrier to providing diabetes-related services was the perception that some physicians and patients have of pharmacists as dispensers only.

The present study revealed that pharmacists had a general positive attitude toward diabetes management, which is consistent with findings from previous studies [14-16] that used DAS-3 as a tool to measure pharmacists' diabetes-related attitudes. However, younger pharmacists

Med Princ Pract 2017;26:273-279 DOI: $10.1159 / 000456088$ 
showed significantly more positive attitudes towards the need for special training compared to older pharmacists because of their inexperience. This is consistent with a previous study [20] in which it was reported that younger and less experienced pharmacists were less prepared to perform patient education and other pharmaceutical care duties. Evidence has shown that people express their attitudes according to the knowledge gained throughout their lives [21]. Additionally, it was found that pharmacists who graduated from Kuwait University showed significantly more positive attitudes towards the following subscales: the need for special training, the severity of type 2 diabetes, and the value of tight control compared to non-Kuwait University pharmacists. This is consistent with a previous study, which indicated that pharmacy students in Kuwait University had positive attitudes and perceived that they were well prepared to provide pharmaceutical care to patients in Kuwait [22].

Despite their general positive attitude towards diabetes management, pharmacists in this study reported that they regularly provided patients with counseling about the appropriate time to administer medication; but not diabetes services related to hypoglycemia and comorbid disease management. This is consistent with previous reports that only basic diabetes services, such as patient counseling was given on a regular basis $[15,16]$, but not the more complex tasks such as reviewing patients' drug profiles to identify causes for poor blood pressure control. Equally important, pharmacists in both primary and secondary health care systems provided similar activities to patients with diabetes despite different caseloads. This might be due to the lack of local guidelines clarifying the accepted duties for pharmacists in wards or dispensaries, which may prevent pharmacists from participating in wider clinical roles in hospitals in Kuwait. Such guidelines and job descriptions are necessary for the improvement of pharmacy practice in Kuwait [17]. Hence, it is necessary to have a collaborative multilevel actions that could involve a broad stakeholder group to improve pharmaceutical care services provided to patients in $\mathrm{Ku}$ wait. Stakeholders could include the Ministry of Health as a policymaker, directors of hospitals and primary care centers as the managers of health care services, pharmacists as health care providers, and the Faculty of Pharmacy as the only public school in Kuwait.

In this study, there was a negative correlation between overall DAS-3 scores/three DAS-3 subscales, and some of the diabetes-related services, which is consistent with a previous study [15] that identified a negative correlation between the attitudes toward the difficulty of treating dia- betes and pharmacists' involvement in patient education. This negative correlation could indicate that pharmacists were not active in providing diabetes-related services to patients despite their beliefs that diabetes needs extensive patient education. This might be due to the less confidence of the study participants in applying the knowledge and skills that they gained from their pharmacy education. Hence, they suggested the need for special diabetes training directed toward behavioral and communication skills.

The present study revealed that the highest ranked barrier to providing diabetes related services to patients was the perception that some physicians or patients have of pharmacists as dispensers only. This is consistent with other studies $[17,23,24]$ in which it was reported that acceptance from physicians and patients were among the top 5 greatest barriers to providing pharmaceutical care. This might be due to a lack of awareness of the pharmacists' role in direct patient care among health care providers and the public. Hence, the need for closer cooperation between pharmacists and physicians is needed in Kuwait to build trust and confidence between health care professionals [25]. Increased population awareness about the pharmacists' role in the community would also aid in ensuring a wider public acceptance of pharmacists' contributions to patient care [26].

The limitations of this study included the convenience sampling strategy based on only 1 health region out of the 6 health care regions in Kuwait. The cross-sectional design represented 1 point in time and, therefore, could not reflect any dynamic changes in respondents' attitudes and practice. In addition, respondents might have offered favorable answers to conform to the more socially accepted view. Responses were taken at face value with no way of verifying respondents' claims.

\section{Conclusions}

This study demonstrated that pharmacists had positive diabetes-related attitudes; however, they provided limited diabetes-related services to patients. Barriers to providing increased pharmaceutical care services to patients with diabetes should be addressed to enable delivery of optimum care for people with diabetes in Kuwait.

\section{Acknowledgement}

The authors would like to thank Fajer Al-Kandari and Fatma Ashkanani for their technical assistance, and all the pharmacists who participated in this research project.
Al Haqan/Al-Taweel/Awad/Wake 


\section{References}

1 Department of Health: Management of medicines: a resource to support implementation of the wider aspects of medicines management for the National Service Frameworks for Diabetes, Renal Services and Long-Term Conditions. http://webarchive.nationalarchives.gov.uk/20130107105354/http://www. dh.gov.uk/prod_consum_dh/groups/dh_ digitalassets/@dh/@en/documents/digitalasset/dh_4088755.pdf (accessed July 7, 2015).

2 American Diabetes Association: Standards of medical care in diabetes: strategies for improving care. Diabetes Care 2016;39(suppl 1): S6-S12.

3 Farsaei S, Sabzghabaee AM, Zargarzadeh AH, et al: Effect of pharmacist-led patient education on glycemic control of type 2 diabetics: a randomized controlled trial. J Res Med Sci 2011;16:43-49.

4 Choe HM, Mitrovich S, Dubay D, et al: Proactive case management of high-risk patients with type 2 diabetes mellitus by a clinical pharmacist: a randomized controlled trial. Am J Manag Care 2005;11:253-260.

5 Wubben DP, Vivian EM: Effects of pharmacist outpatient interventions on adults with diabetes mellitus: a systematic review. Pharmacotherapy 2008;28:421-436.

6 Jameson JP, Baty PJ: Pharmacist collaborative management of poorly controlled diabetes mellitus: a randomized controlled trial. Am J Manag Care 2010;16:250-255.

7 Campbell RK: Role of the pharmacist in diabetes management. Am J Health Syst Pharm 2002;59(suppl 9):S18-S21.

8 Jennings DL, Ragucci KR, Chumney EC, et al: Impact of clinical pharmacist intervention on diabetes related quality-of-life in an ambulatory care clinic. Pharm Pract (Granada) 2007; 5:169-173.
9 Cranor CW, Christensen DB: The Asheville Project: short-term outcomes of a community pharmacy diabetes care program. J Am Pharm Assoc 2003;43:149-159.

10 Pousinho S, Morgado M, Falcao A, et al: Pharmacist interventions in the management of type 2 diabetes mellitus: a systematic review of randomized controlled trials. J Manag Care Spec Pharm 2016;22:493-515.

11 US Department of Health, Education, and Welfare, Public Health Service: National Institutes of Health Report of the National Commission on Diabetes to the Congress of the United States, vol. 3. https://archive.org/details/reportofnational313unit (accessed March 19, 2015).

12 Anderson RM, Donnelly MB, Gressard CP et al: Development of diabetes attitude scale for health-care professionals. Diabetes Care 1989;12:120-127.

13 Anderson RM, Fitzgerald JT, Funnell MM, et al: The third version of the diabetes attitude scale. Diabetes Care 1998;21:1403-1407.

14 Schapansky LM, Johnson JA: Pharmacists' attitudes toward diabetes. J Am Pharm Assoc 2000;40:371-377.

15 Younis WS, Campbell S, Slack MK: Pharmacists' attitudes toward diabetes and their involvement in diabetes education. Ann Pharmacother 2001;35:841-845.

16 Simpson H, Haggarty H, Johnson J, et al: Survey of pharmacist activities and attitudes in diabetes management. Can Pharm J 2009;142: 128-134.

17 Al-Taweel D, Awad A, Johnson BJ: Pharmacists' contributions to the delivery of pharmaceutical care to patients with type 2 diabetes in Kuwait. Int J Diabetes Dev Ctries 2014;34: 108-115.
18 State of Kuwait: General Statistics Bureau. Statistical Review, ed 36. https://www.e.gov. $\mathrm{kw} /$ sites/kgoenglish/Forms/Statistical Review-2013.pdf (accessed September 30, 2016).

19 Chisholm-Burns MA, Kim Lee J, Spivey CA et al: US pharmacists' effect as team members on patient care: systematic review and metaanalyses. Med Care 2010;48:923-933.

20 Katoue MG, Awad A, Schwinghammer TL, et al: Pharmaceutical care in Kuwait: hospital pharmacists' perspectives. Int J Clin Pharm 2014;36,1170-1178.

21 Tesser A, Schwarz N (eds): Handbook of Social Psychology: Intraindividual Processes. Oxford, Blackwell, 2001, pp 463-457.

22 Katoue MG, Awad AI, Schwinghammer TL, et al: Pharmaceutical care education in $\mathrm{Ku}$ wait: pharmacy students' perspectives. Pharm Pract 2014;12:411-418.

23 Aburuz S, Al-Ghazawi M, Snyder A: Pharmaceutical care in a community-based practice setting in Jordan: where are we now with our attitudes and perceived barriers? J Pharm Pract 2012;20:71-79.

24 Al-Arifi M, Al-Dhuwaili A, Gubara O, et al: Pharmacists' understanding and attitudes towards pharmaceutical care in Saudi Arabia. Saudi Pharm J 2007;15:146-159.

25 Matowe L, Abahussain E, Al-Saffar N, et al: Physicians' perceptions and expectations of pharmacists' professional duties in government hospitals in Kuwait. Med Princ Pract 2006;15:185-189.

26 Awad A, Waheedi M: Community pharmacists role in obesity treatment in Kuwait: a cross-sectional study. BMC Public Health 2012;12:863-872. 